\title{
Characteristics of freeze-concentrated apple cider fermented using mixed culture of non-Saccharomyces and Saccharomyces cerevisiae Fermivin
}

\author{
Hyun-Jeong Wee ${ }^{1}$, Sae-Byuk Lee ${ }^{2}$, Kyu-Taek Choi ${ }^{2}, \mathrm{Ji}^{-}$Yeon $\mathrm{Ham}^{2}$, \\ Soo-Hwan Yeo ${ }^{3}$, Heui-Dong Park ${ }^{1,2,4 *}$ \\ ${ }^{1}$ Department of Fermentation Biotechnology, Graduate School, Kyungpook National University, Daegu 41566, Korea \\ ${ }^{2}$ School of Food Science and Biotechnology, Kyungpook National University, Daegu 41566, Korea \\ ${ }^{3}$ Fermented Food Science Division, Department of Agro-Food Resources, NIAS, RDA, Wanju 55365, Korea \\ ${ }^{4}$ Institute of Fermentation Biotechnology, Kyungpook National University, Daegu 41566, Korea
}

\section{Non-Saccharomyces와 Saccharomyces cerevisiae Fermivin으로 혼합 발효한 사과와인의 동결농축에 따른 이화학적 특성}

\author{
위현정 ${ }^{1} \cdot$ 이새벽 ${ }^{2} \cdot$ 최규택 ${ }^{2} \cdot$ 함지연 $^{2} \cdot$ 여수환 $^{3} \cdot$ 박희동 $^{1,2,4 *}$ \\ ${ }^{1}$ 경북대학교 발효생물공학과, ${ }^{2}$ 경북대학교 식품공학부, ${ }^{3}$ 농촌진흥청 국립농업과학원 농식품자원부, \\ 경북대학교 발효생물공학연구소
}

\begin{abstract}
The aim of this study was to develop high quality no-sugar-added apple cider. Physicochemical characteristics of the apple cider fermented using a co-culture of Saccharomyces cerevisiae Fermivin and non-Saccharomyces yeasts (Pichia anomala JK04 and Issatchenkia orientalis KMBL5774) were investigated after freeze concentration (FC) until alcohol content reached $12 \%$ (v/v). Compared with others, JK04 cider showed delayed alcohol fermentation. Soluble solid, reducing sugar, total acidity, and total phenolic compounds including free-sugar content of JK04 cider were considerably increased after FC compared to those of other ciders. Malic acid content was the highest among organic acids in all ciders after FC, while lactic acid content remained unchanged. Methanol, acetaldehyde, and fusel oil content of all ciders increased after FC; but it was lower than the standard of Korean Food Standards Codex. Hue value decreased in Fermivin and JK04 ciders but increased in $\mathbf{5 7 7 4}$ cider. Intensity values of all ciders increased. $L$ and a values in all ciders decreased, whereas $b$ value increased remarkably. In total, 20 types of volatile aromatic compounds were detected. High molecular weight compounds increased while low molecular weight compounds decreased after FC. JK04 cider got the highest color and flavor scores, while 5774 cider got the highest taste and overall preferences scores. Therefore, these data show that non-Saccharomyces yeasts and freeze concentration can be used to improve the overall quality of apple cider.
\end{abstract}

Key words : apple cider, non-Saccharomyces yeasts, co-fermentation, freeze-concentration, fermentation

서 론

*Corresponding author. E-mail : hpark@knu.ac.kr

Phone : 82-53-950-5774, Fax : 82-53-950-6772

Received 21 August 2018; Revised 10 September 2018; Accepted 11 September 2018.

Copyright (c) The Korean Society of Food Preservation. All
사과(Malus pumila var dulcissima)는 우리나라 대표적 과일 중 하나로 분류학상으로 장미과에 속하는 다년생 목본 식물이다. 사과는 영양학적 우수성이나 기능성에서는 매우 뛰어나지만, 생과실로 유통되는 중 발생하는 품질저하의 억제, 상품성 유지와 유통기한 연장에 많은 어려움이 있는 실정이다(1). 대부분의 사과는 생과로 소비되며(85\%) 그

rights reserved. 
중 상품성이 없는 $10-15 \%$ 정도만 가공용 원료로서 사용되 고 있다. 가공용 사과는 주로 사과 주스로 가공되어 소비되 었으나 사과 주스 시장의 침체로 활용되지 못하고 있는 실정이며, 최근 오렌지, 키위 등 수입과실의 영향으로 사과 의 수요 또한 감소되고 있다(2). 이에 사과의 효율적 가공방 안이 절실히 요구되고 있다. 사과를 이용한 가공품은 주스, 잼 등이 있으며 그 중 사과와인은 고부가가치 제품으로 충분한 시장성이 있다고 판단되며, 사과와인의 품질 향상 에 따른 경쟁력 확보를 위해서 체계적인 연구가 필요하다 (3).

서양에서는 사과를 이용하여 발효한 후 알코올 함량이 5.5-12\% 정도인 음료를 사과와인이라 하며(4), 프랑스에서 는 'cider, marchand, boisson' 등으로 불리고 독일에서는 'apfel wein, champagner apfel wein' 등으로 불린다. 우리나 라에서는 1969년 최초의 과실주로 등장한 뒤 인기를 얻었 지만, 현재는 농가에서 소규모로 생산, 판매되고 있다(5). 사과 와인에 대한 국내 연구로는 국산 포도로부터 분리한 알코올 효모로 발효한 사과주의 발효 특성(6), 아이스 와인 제조를 위한 동결농축 사과즙의 알코올 발효 특성(7), 사과 와 해당화의 혼합발효로 만든 사과해당화주의 발효특성 (8), 무가당 아이스 와인 제조를 위한 동결농축 사과즙의 알코올 발효특성(9) 등이 있으나, 여전히 사과와인 품질 향상에 관한 연구가 미흡한 실정이다.

동결농축 기술은 식품 또는 용액의 온도를 어는점 이하 로 냉동시켜 물을 얼음 결정의 형태로 만든 다음, 얼음을 분리, 제거하는 방법으로써 다양한 식품분야에서 적용되어 오고 있다(10-12). 또한 동결농축 처리를 반복하면 농축액 의 농도를 더 높일 수 있는데 다른 농축 기술들과 비교하여 가열에 따른 성분 변화가 적어 고품질 와인 제조에 있어 효과적이다(13,14).

와인의 발전에 효모가 기여하는 기능성에 대하여 여러 연구가 진행되고 있는데 특히 발효 중 non-Saccharomyces 와인효모가 와인의 품질향상에 미치는 영향에 대하여 많은 연구가 이루어지고 있다 $(15,16)$. 본 연구의 사용 균주는 non-Saccharomyces로써 와인제조에 있어 향미를 좋게 하여 주질 향상에 도움이 된다고 알려진 Pichia anomala $\mathrm{JK} 04(15)$ 와 malic acid 분해효모인 Issatchenkia orientalis KMBL5774(17), 그리고 대조구로써 상업용 와인효모인 Saccharomyces cerevisiae Fermivin을 사용하였다. NonSaccharomyces 효모들을 단독균주로 사용할 경우 Saccharomyces cerevisiae에 비해 당 발효력이 낮고(15,18), 알코올 생성력이 약하므로 이를 보완하기 위해 각각의 non-Saccharomyces 균주들을 S. cerevisiae Fermivin과 $1: 9(\mathrm{v} / \mathrm{v})$ 의 비율로 혼합하여 접종하였다. 혼합비율의 경우, 사전 예비실험을 통해 실험에 가장 적합하다고 판단되는 비율을 사용하였다.

이에 본 연구에서는 설탕을 가당하지 않은 순수 사과즙
에 non-Saccharomyces 효모를 접종하여 발효시킨 후 동결 농축 기술을 이용하여 알코올 함량이 $12 \%(\mathrm{v} / \mathrm{v})$ 인 고품질의 무가당 사과와인을 제조하여 동결농축 전후 이화학적 특성 에 대해 조사하였다. 또한, 사과와인만의 차별화된 맛과 향을 극대화하기 위한 연구로 사과와인에 최적화된 발효 효모를 사용하여 관능특성 개선을 위한 연구를 실시하였 다.

\section{재료 및 방법}

\section{실험재료 및 균주의 배양조건}

실험에 사용된 원료 사과는 2015년 9월 경북 청송에서 수확한 fuji를 사용하였으며, 필요에 따라 $4^{\circ} \mathrm{C}$ 에서 저온보관 하면서 사용하였다. 실험에 사용한 균주는 경북대학교 식 품공학부 미생물공학연구실에서 분리 및 보관 중인 향미 증진 효과가 있는 $P$. anomala JK04(15)와 malic acid 분해효 모인 I. orientalis KMBL5774(19), 그리고 상업용 와인 효모 인 $S$. cerevisiae Fermivin(DSM Food Specialties, Delft, Netherlands)을 사용하였다. Non-Saccharomyces의 낮은 발 효력을 보완하기 위해 각 non-Saccharomyces 효모를 $S$. cerevisiae Fermivin과 1:9(v/v)의 비율로 혼합하여 사용하였 으며, 대조구는 S. cerevisiae Fermivin 단독발효된 사과와인 을 사용하였다. 이 균주들을 YPD 배지(1.0\% yeast extract, $2.0 \%$ peptone, $2.0 \%$ glucose)를 사용하여 $30^{\circ} \mathrm{C}$ 에서 $150 \mathrm{rpm}$, 48 시간 동안 진탕 배양한 후 원심분리기(SUPRA 22k PLUS, Hanil, Daejeon, Korea)로 8,000 rpm, $15 \mathrm{~min}$ 간 집균한 균체 를 실험에 사용하였다.

\section{동결농축 사과와인의 제조}

사과와인의 제조를 위해 원료 $5 \mathrm{~kg}$ 을 세척 및 착즙한 후 갈변 및 발효과정 중 잡균의 오염 방지를 위해 $200 \mathrm{ppm}$ 의 potassium metabisulfite $\left(\mathrm{K}_{2} \mathrm{~S}_{2} \mathrm{O}_{5}\right)$ 를 첨가하여 사과즙을 제조 하였다. 사과즙의 청징 및 농축액 제조 시 점도 저하를 위해 Rapidase press L(DSM Food Specialties, Delft, Netherlands) 을 $200 \mathrm{ppm}$ 첨가하여 $40^{\circ} \mathrm{C}$ 에서 $150 \mathrm{rpm}, 2$ 시간 동안 효소처 리 한 뒤, $85^{\circ} \mathrm{C}$ 에서 3 분간 가열하여 효소를 불활성화 시켰다 (20). 주모 제작을 위해 본 배양의 $5 \%(\mathrm{v} / \mathrm{v})$ 에 해당하는 사과 즙을 원료로 사용하였다. 이를 위해 YPD 배지에서 $S$. cerevisiae Fermivin, $P$. anomala JK04, I. orientalis KMBL5774를 각각 배양한 후 원심분리하여 얻은 균체를 사과즙에 접종시켜 $30^{\circ} \mathrm{C}, 150 \mathrm{rpm}$ 에서 배양하였으며, 당도 가 $1 / 3$ 정도로 감소하는 시점을 주모 적정 시기로 판단하였 다. 각각 배양된 주모는 $S$. cerevisiae Fermivin과 nonSaccharomyces 효모의 비율을 1:9(v/v)로 접종하여 본 배양 을 실시하였으며, 덧 담금일을 시작점으로 하여 사과와인 의 알코올 발효 특성 및 품질 변화를 조사하였다. 발효는 
$20^{\circ} \mathrm{C}$ 에서 진행되었으며, 알코올 함량이 최대치에 도달한 것으로 판단되었을 때 발효를 종료하였다(3). 완성된 사과 와인은 $8,000 \mathrm{rpm}$ 에서 15 분간 원심분리하여 균체 및 잔여물 을 제거하고 $4^{\circ} \mathrm{C}$ 의 저장실에서 저장 및 실험을 진행하였다. 사과와인의 알코올 함량을 증가시키기 위하여 $4^{\circ} \mathrm{C}$ 에 저장 중인 사과와인을 각각의 냉동용기에 분배한 후, $-20^{\circ} \mathrm{C}$ 에서 48 시간 동안 동결시켰다. 동결된 사과즙은 상온에서 서서 히 해동시키며 일반 시판 와인의 알코올 농도인 $12 \%(\mathrm{v} / \mathrm{v})$ 에 도달할 때까지 유효성분을 농축시켰다.

\section{사과와인의 발효에 따른 농축 특성 분석}

사과와인의 발효과정 중 주질 분석은 발효 중인 와인의 일부를 취하여 원심분리하여 얻은 상징액을 이용하였다. 당도의 측정은 굴절당도계 $\left(\mathrm{N}-1_{a}\right.$, ATAGO Co., Kyoto, Japan)를 사용하였다. 환원당 함량 측정은 dinitrosalicylic $\operatorname{acid}(\mathrm{DNS})$ 시약을 사용하여 비색 정량법으로 측정하였다 (21). 즉, 적당히 희석시킨 상징액 $0.3 \mathrm{~mL}$ 에 $\mathrm{DNS}$ 시약 1 $\mathrm{mL}$ 를 첨가하고 끓는 물에서 5 분간 반응시킨 후, 증류수 $7 \mathrm{~mL}$ 를 첨가하여 분광광도계(UV-1700, Shimazdu Co., Kyoto, Japan)를 사용하여 $550 \mathrm{~nm}$ 에서 흡광도를 측정하였 고, glucose 표준 곡선으로부터 환원당 함량을 환산하였다. 알코올 함량은 국세청주류분석규정에 따라 증류한 후 주정 계로 측정하였다(22). $\mathrm{pH}$ 는 $\mathrm{pH}$ meter(Model 340, Mettler Toledo Co., Schwerzenbach, Germany)를 이용하여 측정하 였고, 총산은 $\mathrm{AOAC}$ 방법에 따라 상징액을 $0.1 \mathrm{~N} \mathrm{NaOH}$ 로 적정하여 사과산(malic acid)으로 환산하였다(23). 사과와 인의 총 페놀성 화합물의 함량 측정은 Folin-Denis법에 의하 여 비색정량 하였다(24,25).

\section{유리당 및 유기산 함량}

유리당과 유기산 함량은 사과와인을 membrane filter (Millex-HV $0.45 \mu \mathrm{m}$, Millipore Co., Bedford, MA, USA)로 여과시킨 후 HPLC(600E, Waters, Milford, MA, USA)를 이용하여 분석하였다(26). 유리당 column은 Sugar-Pak I $(\phi$ $6.5 \times 300 \mathrm{~mm})$ 을 사용하였고, column 온도는 $90^{\circ} \mathrm{C}$ 로 설정하 였다. 유기산 column은 PL Hi-Plex H $(\$ 7.7 \times 300 \mathrm{~mm})$ 를 사용 하였고, column 온도는 $65^{\circ} \mathrm{C}$ 로 설정하였다.

\section{알데히드, 메탄올 및 퓨젤유 함량}

알데히드, 메탄올 및 퓨젤유 함량은 증류된 사과와인을 $0.45 \mu \mathrm{m}$ membrane filter로 여과한 뒤, gas chromatograph (6890N, Agilent Technologies Inc., Santa Clara, CA, USA)와 FID 검출기(Agilent Technologies Inc.)를 이용하여 분석하 였다(19). Column으로는 $\operatorname{HP}-\mathrm{FFAP}(\Phi \quad 0.25 \times 300$ $\mathrm{mm})$ (Agilent Technologies Inc.)를 사용하였고 column 온도 는 $60^{\circ} \mathrm{C}(4 \mathrm{~min}), 210^{\circ} \mathrm{C}\left(6^{\circ} \mathrm{C} / \mathrm{min}\right), 210^{\circ} \mathrm{C}(2 \mathrm{~min})$ 으로 설정하였 다. Injector 온도는 $190^{\circ} \mathrm{C}$, carrier gas는 $\mathrm{H}_{2}$ 를 사용하였으며 split ratio는 100:1, flow rate는 $30 \mathrm{~mL} / \mathrm{min}$ 이었으며 detector 온도는 $200^{\circ} \mathrm{C}$ 이었다. 각 피크의 동정은 표준품의 retention time과 비교하였고 함량은 피크의 면적으로 계산하였다.

\section{휘발성 향기 성분}

휘발성 향기 성분은 FID가 장착된 gas chromatograph mass spectrometry(Agilent 7890A, Santa Clara, CA, USA)를 사용하여 분석하였고, 향기 성분의 포집은 SPME fiber (50/30 $1 \mathrm{~m}$ DVB/CAR/PDMS, Supelco, Bellefonte, PA, USA) 를 사용하여 head-space 분석법으로 분석하였다(26). 전처 리 방법으로는 headspace vial(20 mm, PTFE/silicon septum, magnetic cap)에 시료 $5 \mathrm{~mL}$ 와 $25 \% \mathrm{NaCl}(\mathrm{w} / \mathrm{v})$ 을 첨가하여 완벽하게 밀봉한 후 $35^{\circ} \mathrm{C}$ 에서 자력교반기로 20 분 동안 교반 하여 시료와 headspace의 휘발성 성분이 평형이 이루어졌 을 때 SPME fiber를 주입하여 40분간 향기 성분을 포집하였 다. 휘발성 향기 성분 분석을 위한 column은 DB-WAX(60 $\mathrm{m} \times 250 \mu \mathrm{m} \times \phi 0.25 \mathrm{~mm}, \mathrm{Waters})$ 를 사용하였고 column온도 는 $40^{\circ} \mathrm{C}(2 \mathrm{~min}), 220^{\circ} \mathrm{C}\left(2{ }^{\circ} \mathrm{C} / \mathrm{min}\right), 240^{\circ} \mathrm{C}\left(20^{\circ} \mathrm{C} / \mathrm{min}\right), 240^{\circ} \mathrm{C}(5$ $\mathrm{min}$ )으로 설정하였다. Injector 온도는 $240^{\circ} \mathrm{C}$, carrier gas는 $\mathrm{He}$ 를 사용하였다. 휘발성 향기 성분의 분석을 위해 사용된 library는 Wiley9Nist0.8(Wiley9Nist0.8 Library, mass spectral search program, version 5.0, Hoboken, NJ, USA)이었다(26).

\section{색도 분석}

농축 전과 후 사과와인의 hue와 intensity는 분광광도계 (UV-1601, Shimadzu Co., Kyoto, Japan)를 사용하여 420 $\mathrm{nm}$ 와 $520 \mathrm{~nm}$ 에서 흡광도를 측정한 다음, hue 값은 420 $\mathrm{nm}$ 와 $520 \mathrm{~nm}$ 의 흡광도 값의 비율 $(420 / 520 \mathrm{~nm})$ 로 하였으며, intensity 값은 $420 \mathrm{~nm}$ 와 $520 \mathrm{~nm}$ 의 합 $(420+520 \mathrm{~nm})$ 으로 하였다. 색도는 표준 백색판으로 보정한 colorimeter (Konica Minolta CM-3600A, Osaka, Japan)을 이용하여 측정 하였고, $\mathrm{L}$ (명도), $\mathrm{a}$ (적색도), $\mathrm{b}$ (황색도) 값으로 나타내었다 (26,27).

\section{관능평가}

사과와인의 관능검사는 대학생과 대학원생 중 본 실험에 관심있는 학생 20 명을 선발하여 무작위로 제시된 시료에 대하여 색, 향, 맛, 신맛, 전반적인 기호도에 대하여 평가하 였다. 7점 척도법으로 평가하였으며, 7점은 매우 좋다, 1점 은 매우 나쁘다로 평가하였다. 본 연구의 관능평가는 경북 대학교 생명윤리심의위원회의 규정에 따라 심의하여 승인 번호(2018-0137)를 받아 진행하였다.

\section{통계처리}

모든 실험 결과는 3회 반복 실시하여 실험 결과를 평균 표준편차로 나타내었고 실험군 간의 유의성을 검정하기 위하여 SAS 통계처리(Statstical Analysis System, SAS 
Insititute Inc., Cary, NC, USA)를 이용한 분산분석 (ANOVA)과 Duncan의 다중범위검증(Duncan's multiple range test, $\mathrm{p}<0.05)$ 으로 유의성을 검증하였다(28). 동결농축 전후 사과와인의 이화학적 특성의 차이는 t-test로 유의성을 검증하였다.

\section{결과 및 고찰}

알코올발효에 따른 사과와인의 이화학적 특성 분석

사과와인의 발효과정 중 당도, 환원당, 알코올, $\mathrm{pH}$, 총산, 총 페놀성 화합물의 변화를 알아본 결과는 Fig. 1과 같다. 원료 사과의 초기 당도는 $14.5{ }^{\circ} \mathrm{Brix}$ 이며, 발효 1 일 차부터 당이 알코올로 전환되어 감소하는 경향을 나타내었다. 알 코올 발효 능력이 뛰어난 $S$ cerevisiae Fermivin 단독발효구 와 I. orientalis KMBL5774 혼합발효구의 경우 발효가 진행 됨에 따라 비슷한 경향으로 당이 감소하였고 최종 당도는 발효 종료 시 5.1-5.2 ${ }^{\circ} \mathrm{Brix}$ 를 나타내었다. 반면 P. anomala $\mathrm{JK} 04$ 혼합발효구의 경우 당 감소가 느리게 진행되었는데 이는 P. anomala $\mathrm{JK} 04$ 가 상대적으로 당을 알코올로 전환하 는 속도가 느려(15) 혼합발효에도 영향을 미친것으로 판단 된다. 느린 알코올 생성으로 사과와인이 중도 오염될 우려 가 있다고 판단되어 발효 11 일 차에 발효를 중단하였고, 최종 당도는 $8.2{ }^{\circ} \mathrm{Brix}$ 를 나타내었다(Fig. 1A), 환원당도
마찬가지로 $P$. anomala JK04 혼합발효구를 제외한 모든 발효 구에서 알코올이 생산되는 발효 1 일 차부터 환원당이 감소하였고, 발효 종료 시 $0.15-0.16 \%$ 로 대부분의 환원당이 소비된 것을 확인할 수 있다. P. anomala JK04 혼합발효의 경우 다른 발효구보다 당 발효능이 떨어져 환원당의 감소가 다소 느렸으며, 발효 종료 시 $3.51 \%$ 의 환원당이 잔존하였다 (Fig. 1B). 알코올 함량의 변화는 당이 감소하기 시작하는 발효 1 일 차부터 알코올이 생성되었다. 발효초기 $S$. cerevisiae Fermivin 단독발효구가 I. orientalis KMBL5774 혼합발효구보다 빠르게 알코올이 생성되었고, 발효 종료 후 최종적으로 $7.5-8.1 \%(\mathrm{v} / \mathrm{v})$ 의 알코올 함량을 나타내었다. P. anomala JK04 혼합발효구의 경우 느린 발효 진행으로 오염 가능성이 있다고 판단되어 11 일 차에 발효를 종료하 였으며, $5.2 \%(\mathrm{v} / \mathrm{v})$ 의 최종 알코올 함량을 나타내었다(Fig. 1C).

$\mathrm{pH}$ 는 색, 향, 맛, 그리고 미생물학적 안전성 및 단백질 안정성 등에 직접 영향을 미치므로 전반적인 품질에 중요한 요인이다(29). 포도주 발효나 저장에 있어서 권장되는 $\mathrm{pH}$ 의 범위는 3.2-3.5로서 이 범위를 벗어나게 되면 잡균의 오염이나 신맛이 증가해 제품에 나쁜 영향을 준다고 한다 $(30,31)$. 사과와인의 $\mathrm{pH}$ 의 변화는 $\mathrm{pH} 4.22-4.26$ 에서 대부분 비슷한 경향으로 감소하였고, 발효 종료 시 $\mathrm{pH} 4,06-4.10$ 를 나타내었다(Fig. 1D). 이는 포도주의 권장 $\mathrm{pH}$ 인 3.5보다 높은 수치를 나타내었지만, 기존 사과와인의 연구결과와
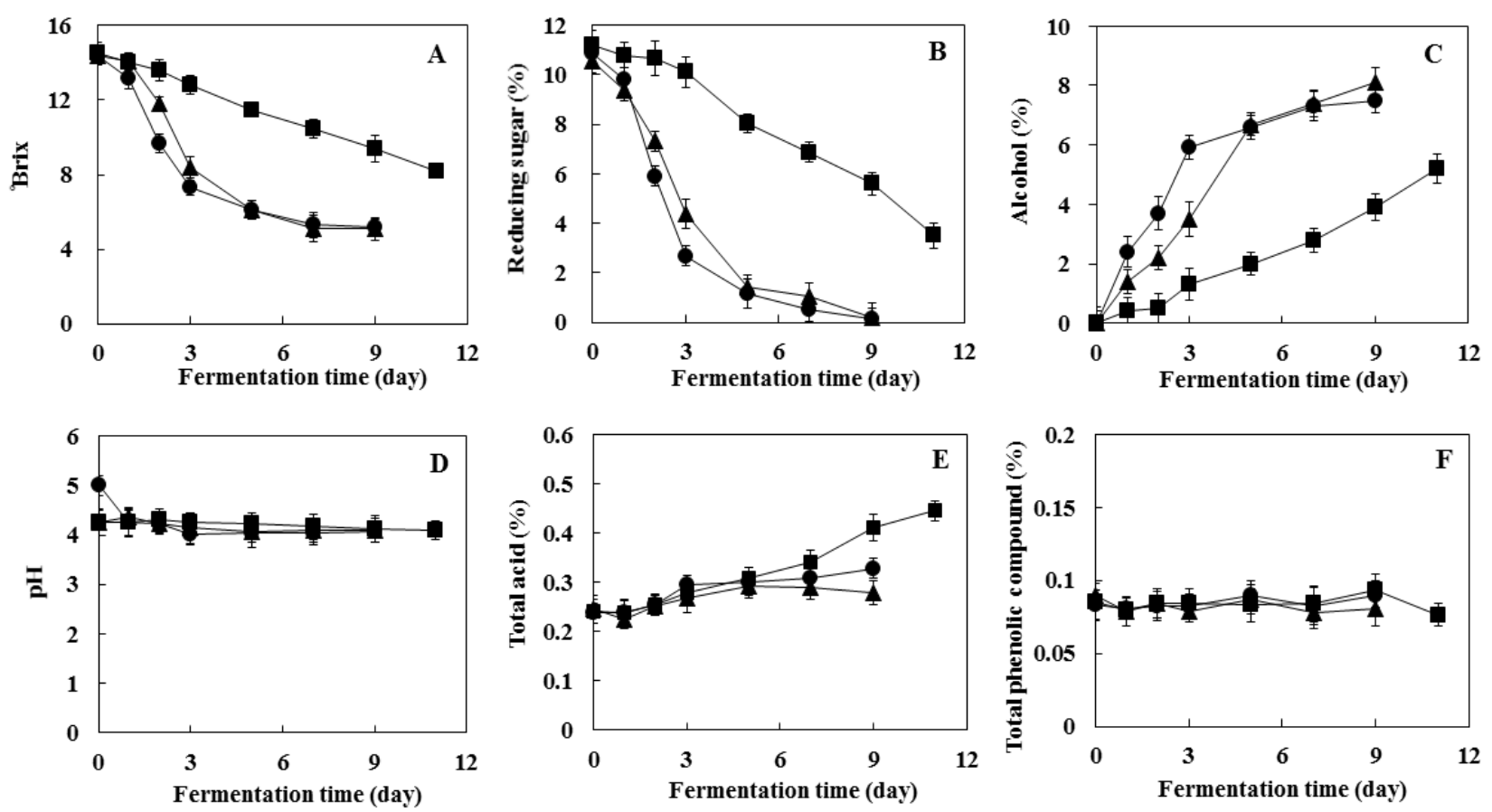

Fig. 1. Changes in the soluble solid content (A), reducing sugar content (B), alcohol content (C), pH (D), total acid content (E), and total phenolic compound (F) of apple ciders fermented by single fermentation with Saccharomyces cerevisiae W-3 (O), mixed fermentation with $\boldsymbol{S}$. cerevisiae Fermivin and Pichia anomala JK04 ( $\square$ ), and mixed fermentation with $\boldsymbol{S}$. cerevisiae Fermivin and Issatchenkia orientalis KMBL5774 (A) during alcohol fermentation. 
비슷한 값을 나타내어 원재료의 특성 차이인 것으로 사료된 다(32). I. orientalis KMBL5774 혼합발효구의 경우, 알코올 발효 동안 다른 발효구들 보다 약간 높은 $\mathrm{pH}$ 값을 나타내었 는데, 이는 I. orientalis KMBL5774의 malic acid 분해력에 의한 감산효과의 영향으로 판단된다. 모든 발효구의 초기 총산은 $0.24 \%$ 였으며, 발효 2 일 차부터 총산이 증가하였다. S. cerevisiae Fermivin 단독발효구는 발효가 진행됨에 따라 총산이 꾸준히 증가하였고, 발효 종료 시 $0.33 \%$ 로 나타났 다. 이와 비슷한 경향으로 P. anomala JK04 혼합발효구의 산도도 발효 진행에 따라 증가하였고, 발효 종료 시 $0.45 \%$ 로 가장 높은 총산을 나타내었다. I. orientalis KMBL5774 혼합발효구의 경우 발효 5 일 차까지 $0.29 \%$ 로 총산함량이 증가하였다가 발효 종료 시 $0.27 \%$ 로 조금 감소하는 양상을 보였는데, 이는 I. orientalis KMBL5774의 감산효과로 인해 발효 후기에 총산이 감소되는 것으로 판단된다(Fig. $1 \mathrm{E}$ ). 총 페놀성 화합물은 색소와 탄닌성 물질을 구성하며, 색, 향, 맛 등 관능적인 특성과 숙성에 중요한 요인으로 작용한 다(9). 사과와인에는 총 페놀성 화합물질이 풍부하게 함유 되어있으며, 이러한 총 페놀성 화합물의 생화학적인 효과 로 인해 사과와인의 건강기능성을 유도한다고 알려져 있다 $(33,34)$. 또한 사과와인의 총 페놀성 화합물의 함량은 사과 품종, 양조기술, 발효온도 및 착즙 등에 의해 큰 영향을 받는다는 보고가 있다(9). 모든 발효구들은 발효 0 일 차에
0.083-0.089\%의 총 페놀성 화합물 함량을 나타내었으며, 발효가 진행됨에 따라 큰 차이는 발견되지 않았다. 발효 종료 후 S. cerevisiae Fermivin 단독발효구는 $0.090 \%$ 로 가장 높은 함량을 나타내었으며, P. anomala JK04 혼합발효구와 I. orientalis KMBL5774 혼합발효구의 경우, 0.076-0.081\% 로 조금 감소하였다(Fig. 1F).

\section{동결농축에 따른 사과와인의 이화학적 특성 분석}

사과와인의 동결농축에 따른 당도, 환원당, 알코올, $\mathrm{pH}$, 총산, 총 페놀성 화합물 함량의 변화는 Fig. 2 와 같다. 일반 상업용 와인의 알코올 함량인 $12 \%(\mathrm{v} / \mathrm{v})$ 까지 농축하였으며, 농축 후 당도는 $S$. cerevisiae Fermivin 단독발효구와 $I$. orientalis KMBL5774 혼합발효구의 경우 8.2-8.4 ${ }^{\circ} \mathrm{Brix}$ 로 농축되었으며, P. anomala JK04 혼합발효구의 경우 18.4 ${ }^{\circ} \mathrm{Brix}$ 로 농축되었다(Fig. 2A). 환원당 함량은 모든 구에서 농축에 따라 2 배 정도 증가하였다. 잔당이 남아있었던 $P$. anomala JK04 혼합발효구의 농축 후 환원당이 $8.32 \%$ 로 가장 높은 값을 나타내었고, 발효가 종료되었던 $S$. cerevisiae Fermivin 단독발효구와 I. orientalis KMBL5774 혼합발효구의 경우 0.26-0.27\%로 비슷한 값을 나타내었다 (Fig. 2B). 알코올의 경우 농축 결과 $12.0-12.4 \%$ 의 알코올 함량을 얻었다(Fig. $2 \mathrm{C}$ ). 모든 시료의 $\mathrm{pH}$ 는 동결농축 후 4.10-4.16으로 약간 증가하였으나 큰 차이를 나타내지는
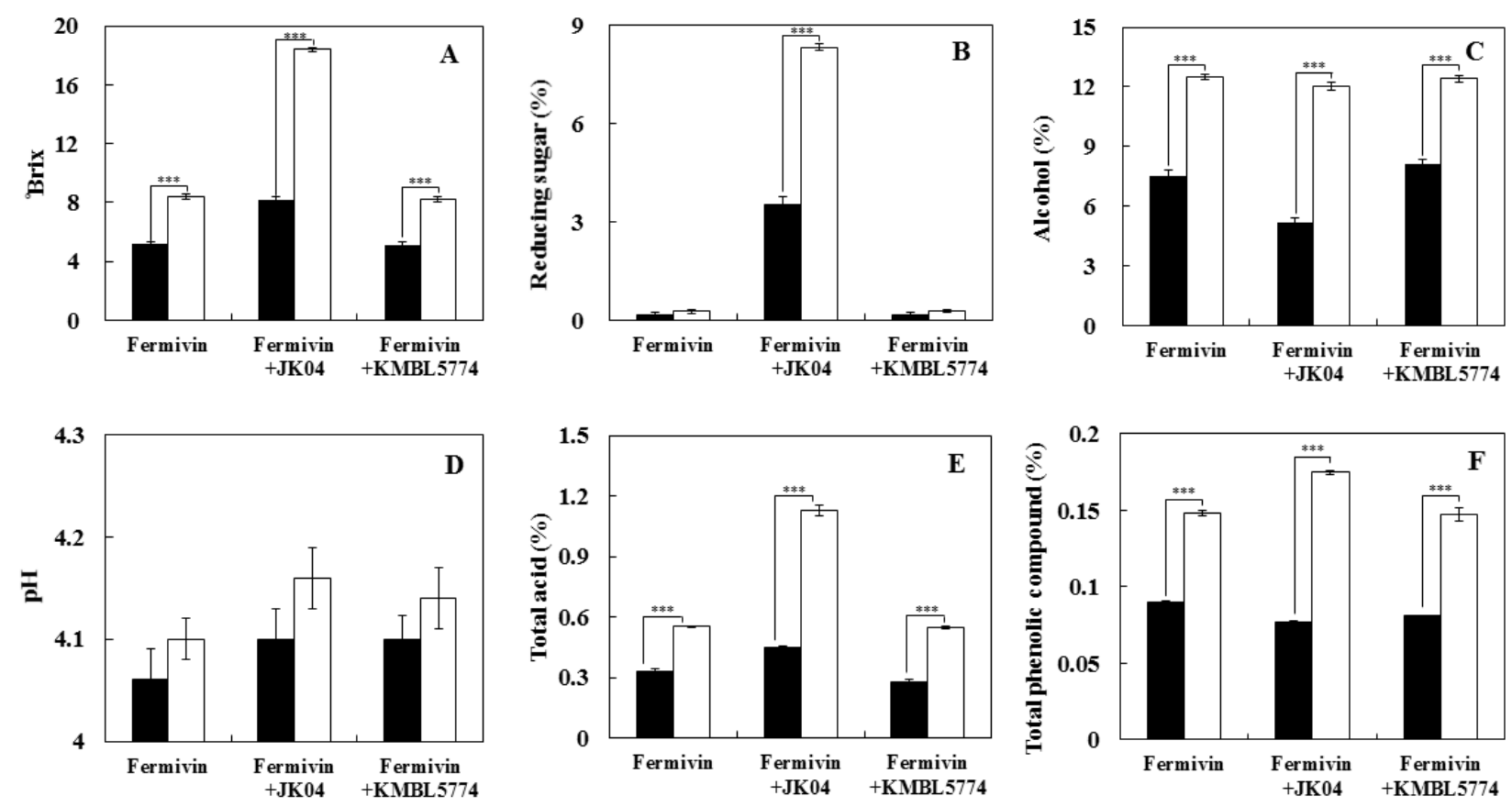

Fig. 2. Changes in the soluble solids content (A), reducing sugar content (B), alcohol content (C), pH (D), total acid content (E), and total phenolic compound (F) of apple ciders fermented by single fermentation with Saccharomyces cerevisiae W-3, mixed fermentation with $S$. cerevisiae Fermivin and Pichia anomala JK04, and mixed fermentation with $S$. cerevisiae Fermivin and Issatchenkia orientalis KMBL5774 before $(\square)$ and after $(\square)$ freeze concentration.

${ }^{* * *} \mathrm{p}<0.001$ is considered statistically significant using a Student's t-test. 
않았다(Fig. 2D). $\mathrm{pH}$ 와는 달리 사과와인의 총산 함량은 동 결농축 이후 $0.22-0.68 \%$ 증가하였는데, 특히 동결농축 전 총산 함량이 $0.45 \%$ 로 가장 높았던 P. anomala JK04 혼합발 효구에서 가장 크게 증가하였는데 이는 초기 알코올 함량이 낮아 다른 발효구보다 더욱 농축을 진행하였기 때문으로 판단된다. I. orientalis KMBL5774 혼합발효구는 동결농축 이후에도 감산효과에 의해 다른 발효구와 비교하여 총산의 함량이 $0.55 \%$ 로 가장 낮았다(Fig. 2E). 모든 발효구의 동결 농축 후 총 페놀성 화합물의 함량은 $0.147-0.175 \%$ 로 농축 전보다 2 배 정도 증가하였고, P. anomala $\mathrm{JK} 04$ 의 혼합발효 구에서 가장 높은 함량을 나타내었으며, 이는 총산 증가와 같은 이유로 판단된다(Fig. $2 \mathrm{~F}$ ).

\section{동결농축에 따른 사과와인의 유리당 및 유기산 함량 분석}

동결농축에 따른 사과와인의 유리당 및 유기산 조성을 분석한 결과를 Table 1에 나타내었다. 동결농축 후 유리당 함량은 동결농축 전과 비교하여 S. cerevisiae Fermivin 단독 발효구에서 sucrose가 약간 감소하였으나 그 폭이 크지 않 았으며, 나머지 모든 시험구에서는 대체로 증가하거나 비 슷한 경향을 나타내었다. 발효가 완전 이루어지지 않은 $P$. anomala JK04 혼합발효구에서는 상대적으로 많은 양의 유 리당이 검출되었으며, 농축 후 2-3배 가량 증가하였다. 사과 와인의 맛과 향, 발효, $\mathrm{pH}$, 와인의 안정성 등은 산의 영향을 크게 받는다. 총산도가 동일하였을 때 malic acid > tartaric acid > citric acid > lactic acid 순으로 산미가 강하게 작용하 여 과실 및 과실주의 신맛에 영향을 미친다고 보고한 바 있다(35). 사과에 함유된 유기산으로는 malic acid, citric acid, succinic acid 등이 주를 이루는데, 그 중 malic acid는 사과산이라고도 하며 천연주스의 색조 유지에 큰 역할을
하고 산미에 긍정적인 영향을 준다(5). 동결농축 후 유기산 함량은 lactic acid를 제외하고 모두 증가하였으며, 특히 malic acid 함량이 모든 시료구에서 크게 증가하였으며, malic acid 감산 능력을 지닌 I. orientalis KMBL5774 혼합발 효구에서 가장 낮은 값을 나타내었다. Acetic acid의 경우, 발효가 상대적으로 지연되었던 P. anomala JK04 혼합발효 구에서 일부 생성되었고, 동결농축 후 수치가 증가하였으 나, 관능에 큰 영향을 미치는 정도로 생성되지는 않았다.

동결농축에 따른 사과와인의 메탄올, 아세트알데히드, 퓨 젤유 함량 변화

동결농축에 따른 사과와인의 메탄올, 알데히드, 퓨젤유 함량 분석 결과를 Table 2에 나타내었다. 메탄올은 과실 중의 pectin methylesterase가 펙틴을 가수분해하여 생성되 기 때문에 과실주의 정상성분이기는 하지만 과량을 섭취한 경우 시신경을 마비시키거나 심하면 생명에 치명적으로 작용할 수 있다(36). 동결농축 후 모든 발효구에서 메탄올 함량이 증가하였으나 식품공전에 명시된 과실주의 메탄올 허용기준치인 $1,000 \mathrm{ppm}$ 보다 낮은 값을 나타내었다(37).

알데히드는 와인에 흔히 존재하는 물질로 와인에 따라 상당량 존재할 수 있으며, 아세트알데히드와 하이드록시메 틸푸르푸랄의 형태가 많다. 와인에 있는 알데히드 중 $90 \%$ 를 아세트알데히드가 차지하며, 알코올 발효의 중간 산물 이지만, 발효 중에 모두 에탄올로 환원된다. 낮은 농도에서 는 과일 향과 같은 좋은 향을 나타내며, 높은 농도에서는 자극적인 향을 나타낸다고 알려져 있다(38). 동결농축 전에 는 S. cerevisiae Fermivin 단독발효구에서, 동결농축 후에는 I. orientalis KMBL5774의 혼합발효구에서 가장 높은 값을 나타내었고, 모든 발효 구에서 농축에 의해 아세트알데히

Table 1. Changes in free sugar and or ganic acid contents of apple ciders fermented by Saccharomyces cerevisiae Fermivin (Fermivin), mixed culture of $S$. cerevisiae Fermivin and Pichia anomala JK04 (Fermivin+JK04), mixed culture of $S$. cerevisiae Fermivin and Issatchenkia orientalis KMBL5774 (Fermivin+KMBL5774) before and after freeze concentration

\begin{tabular}{cccccccccc}
\hline \multirow{2}{*}{ Strains } & & \multicolumn{3}{c}{ Free sugar contents $(\mathrm{g} / \mathrm{L})$} & \multicolumn{4}{c}{ Organic acid contents $(\mathrm{g} / \mathrm{L})$} \\
\cline { 3 - 10 } & & Sucrose & Glucose & Fructose & Citric acid & Tartaric acid & Malic acid & Lactic acid & Acetic acid \\
\hline \multirow{3}{*}{ Fermivin } & Before & $0.20 \pm 0.06^{1)}$ & $0.03 \pm 0.02$ & $0.10 \pm 0.06$ & $0.07 \pm 0.01$ & $0.09 \pm 0.01$ & $0.61 \pm 0.02$ & $0.01 \pm 0.01$ & $0.01 \pm 0.01$ \\
& After & $0.04 \pm 0.03$ & $0.01 \pm 0.01$ & $0.11 \pm 0.09$ & $0.09 \pm 0.01$ & $0.12 \pm 0.03$ & $0.96 \pm 0.04$ & $0.02 \pm 0.01$ & $0.01 \pm 0.00$ \\
& p value ${ }^{2)}$ & $0.014480^{*}$ & 0.196261 & 0.880541 & 0.070484 & 0.175693 & $0.000171^{* * *}$ & 0.287864 & 1 \\
\hline \multirow{2}{*}{ Fermivin+JK04 } & Before & $2.02 \pm 0.21$ & $3.14 \pm 0.17$ & $38.11 \pm 0.89$ & $0.05 \pm 0.01$ & $0.07 \pm 0.01$ & $0.59 \pm 0.05$ & $0.01 \pm 0.01$ & $0.21 \pm 0.05$ \\
& After & $10.04 \pm 2.33$ & $7.03 \pm 1.21$ & $84.38 \pm 6.81$ & $0.14 \pm 0.01$ & $0.16 \pm 0.03$ & $0.96 \pm 0.03$ & $0.01 \pm 0.01$ & $0.49 \pm 0.04$ \\
& p value & $0.017551^{*}$ & $0.031350^{*}$ & $0.007264^{* *}$ & $0.000385^{* * *}$ & $0.007876^{* *}$ & $0.000389^{* * *}$ & 1 & $0.001629^{* *}$ \\
\hline \multirow{3}{*}{ Fermivin+ +} & Before & $0.05 \pm 0.01$ & $0.02 \pm 0.01$ & $0.04 \pm 0.01$ & $0.06 \pm 0.01$ & $0.09 \pm 0.02$ & $0.44 \pm 0.02$ & $0.02 \pm 0.01$ & $0.00 \pm 0.00$ \\
& After & $0.27 \pm 0.04$ & $0.05 \pm 0.01$ & $0.04 \pm 0.01$ & $0.08 \pm 0.01$ & $0.11 \pm 0.03$ & $0.93 \pm 0.02$ & $0.02 \pm 0.01$ & $0.01 \pm 0.01$ \\
& p value & $0.000762^{* * *}$ & $0.021312^{*}$ & 1 & 0.070484 & 0.391076 & $0.000007^{* * *}$ & 1 & 0.225403 \\
\hline
\end{tabular}

${ }^{1)}$ The values were expressed as mean \pm SD ( $n=3$ ).

${ }^{2)} \mathrm{p}$ values were considered statistically significant using a Student's t-test $\left(^{*}, \mathrm{p}<0.05 ;{ }^{* *}, \mathrm{p}<0.01 ;{ }^{* *}, \mathrm{p}<0.001\right)$. 
Table 2. Changes in methanol, acetaldehyde, and fusel oil contents of apple ciders fermented by Saccharomyces cerevisiae Fermivin (Fermivin), mixed culture of $S$. cerevisiae Fermivin and Pichia anomala JK04 (Fermivin+JK04), mixed culture of $S$. cerevisiae Fermivin and Issatchenkia orientalis KMBL5774 (Fermivin+KMBL5774) before and after freeze concentration

\begin{tabular}{|c|c|c|c|c|c|c|}
\hline \multirow{2}{*}{ Strains } & & \multirow{2}{*}{$\begin{array}{l}\text { Methanol } \\
(\mathrm{mg} / \mathrm{L})\end{array}$} & \multirow{2}{*}{$\begin{array}{l}\text { Acetaldehyde } \\
(\mathrm{mg} / \mathrm{L})\end{array}$} & \multicolumn{3}{|c|}{ Fusel oil contents (mg/L) } \\
\hline & & & & Isopropyl alcohol & Isoamyl alcohol & Isobutyl alcohol \\
\hline \multirow{3}{*}{ Fermivin } & Before & $32.11 \pm 1.82^{1)}$ & $149.64 \pm 5.03$ & $114.64 \pm 3.54$ & $\mathrm{ND}^{3)}$ & $163.21 \pm 2.78$ \\
\hline & After & $119.35 \pm 7.09$ & $173.47 \pm 9.36$ & $262.05 \pm 23.87$ & $61.68 \pm 4.25$ & $216.11 \pm 10.27$ \\
\hline & $\mathrm{p}$ value ${ }^{2)}$ & $0.017776^{*}$ & $0.000032^{* \star *}$ & $0.008814^{* *}$ & - & $0.000999^{* * *}$ \\
\hline \multirow{3}{*}{ Fermivin+JK04 } & Before & $42.24 \pm 3.06$ & $132.19 \pm 5.89$ & $\mathrm{ND}$ & ND & $174.55 \pm 10.95$ \\
\hline & After & $264.60 \pm 11.05$ & $105.69 \pm 9.48$ & ND & $131.38 \pm 11.55$ & $370.23 \pm 9.82$ \\
\hline & $\mathrm{p}$ value & $0.014701^{*}$ & $0.000004^{* * \star}$ & - & - & $0.000021^{* \star *}$ \\
\hline \multirow{3}{*}{$\begin{array}{l}\text { Fermivin+ } \\
\text { KMBL5774 }\end{array}$} & Before & $40.65 \pm 1.24$ & $148.18 \pm 6.89$ & ND & ND & $247.64 \pm 20.37$ \\
\hline & After & $142.70 \pm 9.31$ & $202.36 \pm 6.88$ & $\mathrm{ND}$ & $71.88 \pm 9.82$ & $412.62 \pm 11.92$ \\
\hline & $\mathrm{p}$ value & $0.000648^{* \star *}$ & $0.002811^{* *}$ & - & - & $0.000267^{* \star *}$ \\
\hline
\end{tabular}

${ }^{1)}$ The values were expressed as mean \pm SD $(n=3)$.

${ }^{2)} \mathrm{p}$ values were considered statistically significant using a Student's t-test $\left({ }^{\star}, \mathrm{p}<0.05 ;{ }^{* *}, \mathrm{p}<0.01 ;{ }^{* * *}, \mathrm{p}<0.001\right)$.

${ }^{3)} \mathrm{ND}$, not detected.

드의 값이 약간씩 증가하였지만, 식품 공전 기준치인 700 $\mathrm{ppm}$ 보다 매우 낮은 함량으로 나타났다(37).

퓨젤유는 에틸알코올보다 끓는점이 높고 분자 구조상 탄소 수가 많은 복잡한 알코올을 총칭해서 이르는 말로 주류의 품질을 평가하는 중요한 항목이 되는 성분이며 과실 주 제조시에 생성되는 고급 알코올의 양에 따라 flavor와 body 등 포도주 품질에 큰 영향을 미친다(34,39). 주류에서 퓨젤유 함량이 높아지면 향미가 나빠지며, 식도암, 간암, 폐질환 등을 유발할 가능성이 있으며, 퓨젤유의 사슬 길이 에 따라 그 유해성이 증가할 수 있다고 알려져 있으나, 소량 으로 존재할 경우에는 맛과 향을 높이는 역할을 한다고 알려져 있다(40-42). 동결농축 전후로 사과와인의 퓨젤유
함량을 측정한 결과, isopropyl alcohol, isoamyl alcohol 및 isobutyl alcohol이 측정되었다. 모든 발효 구에서 농축 전에 는 퓨젤유의 함량은 검출되지 않거나 미량의 함량을 나타내 었고, 농축 후에는 혼합발효구의 isopropyl alcohol을 제외하 고 모두 증가하는 것으로 나타났다.

동결농축에 따른 사과와인의 관능적 특성 분석

색도는 사과와인의 발효과정 및 숙성정도 예측 등 와인 의 품질을 평가하는 중요한 요소이다(43). 동결농축에 따른 사과와인의 색도 변화를 알아보기 위하여 색도와 갈변도 분석에 이용되는 hue, intensity, Hunter's color value를 측정 하였으며, 그 결과를 Table 3에 나타내었다. Hue value는 $S$. cerevisiae Fermivin 단독발효구와 P. anomala JK04 혼합

Table 3. Changes in color values of apple ciders fermented by Saccharomyces cerevisiae Fermivin (Fermivin), mixed culture of $S$. cerevisiae Fermivin and Pichia anomala JK04 (Fermivin+JK04), mixed culture of $S$. cerevisiae Fermivin and Issatchenkia orientalis KMBL5774 (Fermivin+KMBL5774) before and after freeze concentration

\begin{tabular}{lcccccc}
\hline \multirow{2}{*}{ Strains } & & \multicolumn{3}{c}{ Color } & \multicolumn{3}{c}{ Hunter's color values } \\
\cline { 3 - 7 } & & Hue & Intensity & $\mathrm{L}$ & $\mathrm{a}$ & $\mathrm{b}$ \\
\hline \multirow{3}{*}{ Fermivin } & Before & $3.02 \pm 0.01^{1)}$ & $0.19 \pm 0.02$ & $64.39 \pm 0.03$ & $0.16 \pm 0.05$ & $1.00 \pm 0.01$ \\
& After & $2.88 \pm 0.04$ & $0.36 \pm 0.02$ & $63.24 \pm 0.08$ & $0.04 \pm 0.02$ & $2.28 \pm 0.05$ \\
& p value & $0.004177^{* *}$ & $0.000480^{* * *}$ & $0.000020^{* * *}$ & $0.018153^{*}$ & $0.000002^{* * *}$ \\
\hline \multirow{3}{*}{ Fermivin+JK04 } & Before & $1.53 \pm 0.25$ & $0.35 \pm 0.02$ & $64.79 \pm 0.08$ & $0.03 \pm 0.04$ & $0.86 \pm 0.08$ \\
& After & $1.34 \pm 0.02$ & $0.66 \pm 0.01$ & $63.66 \pm 0.02$ & $-0.55 \pm 0.03$ & $5.16 \pm 0.08$ \\
\hline \multirow{3}{*}{ Fermivin+ } & p value & 0.319836 & $0.000018^{* * *}$ & $0.000019^{* * *}$ & $0.000036^{* * *}$ & $0.000000^{* * *}$ \\
KMBL5774 & Before & $2.60 \pm 0.17$ & $0.20 \pm 0.01$ & $64.46 \pm 0.07$ & $0.06 \pm 0.02$ & $1.64 \pm 0.01$ \\
& After & $2.97 \pm 0.05$ & $0.38 \pm 0.01$ & $63.81 \pm 0.01$ & $-0.04 \pm 0.01$ & $2.71 \pm 0.05$ \\
\hline
\end{tabular}

${ }^{1)}$ The values were expessed as mean $\pm \mathrm{SD}(\mathrm{n}=3)$

${ }^{2)} \mathrm{p}$ values were considered statistically significant using a Student's t-test $\left({ }^{*}, \mathrm{p}<0.05 ;{ }^{* *}, \mathrm{p}<0.01 ;{ }^{* * *}, \mathrm{p}<0.001\right)$. 
Table 4. Changes in volatile aromatic compounds of apple ciders fermented by Saccharomyces cerevisiae Fermivin (Fermivin), mixed culture of $S$. cerevisiae Fermivin and Pichia anomala JK04 (Fermivin+JK04), mixed culture of $S$. cerevisiae Fermivin and Issatchenkia orientalis KMBL5774 (Fermivin+KMBL5774) before and after freeze concentration

(unit: peak area value/1,000)

\begin{tabular}{|c|c|c|c|c|c|c|c|c|}
\hline \multirow[t]{2}{*}{ Compound names } & \multirow[t]{2}{*}{ Odor description } & \multicolumn{2}{|c|}{ Fermivin } & \multicolumn{2}{|c|}{ Fermivin + JK04 } & \multicolumn{2}{|c|}{$\begin{array}{l}\text { Fermivin + } \\
\text { KMBL5774 }\end{array}$} & \multirow[t]{2}{*}{ Ref. } \\
\hline & & Before & After & Before & After & Before & After & \\
\hline \multicolumn{9}{|l|}{ Acids } \\
\hline Acetic acid & Pungent & $\mathrm{ND}^{1)}$ & $\mathrm{ND}$ & 4,672 & 18,507 & $\mathrm{ND}$ & $\mathrm{ND}$ & 49 \\
\hline Octanoic acid & Candy, caramelized, perfumy, fruity, peachy & 13,990 & 4,785 & 1,376 & $\mathrm{ND}$ & $\mathrm{ND}$ & $\mathrm{ND}$ & 50 \\
\hline Decanoic acid & Rancid, fat & 6,505 & 1,514 & 723 & $\mathrm{ND}$ & $\mathrm{ND}$ & ND & 49 \\
\hline \multicolumn{9}{|l|}{ Alcohols } \\
\hline 1-propanol & Ripe fruit, alcohol & 775 & 2,241 & $\mathrm{ND}$ & 2,172 & ND & 2,141 & 49 \\
\hline Isobutyl alcohol & Oily, bitter, green & 4,303 & 11,269 & 2,764 & 12,228 & 4,999 & 8,501 & 49 \\
\hline Isoamyl alcohol & Fusel & 72,916 & 115,190 & 38,654 & 93,150 & 66,713 & 84,271 & 49 \\
\hline 1-Hexanol & Green, grass & 3,923 & 1,764 & 3,336 & 3,488 & 3,394 & 3,307 & 51 \\
\hline 1-Heptanol & Grape, sweet & 871 & ND & $\mathrm{ND}$ & $\mathrm{ND}$ & 955 & ND & 51 \\
\hline Phenethyl alcohol & Floral, rose & ND & $\mathrm{ND}$ & 7,122 & 3,879 & 5,976 & 3,524 & 50 \\
\hline 2-Nonanol & Slightly fruity, pungent & 872 & $\mathrm{ND}$ & $\mathrm{ND}$ & $\mathrm{ND}$ & 713 & 586 & 52 \\
\hline \multicolumn{9}{|l|}{ Esters } \\
\hline Methyl acetate & Fruity, banana, pineapple & ND & $\mathrm{ND}$ & 414 & 610 & ND & $\mathrm{ND}$ & 53 \\
\hline Ethyl acetate & Fruity, sweet & 9,730 & 6,779 & 482,231 & 623,820 & 13,081 & 7,957 & 51 \\
\hline Isobutyl acetate & Fruity, sweet & $\mathrm{ND}$ & ND & 1,131 & 1,792 & 504 & $\mathrm{ND}$ & 54 \\
\hline Isoamyl acetate & Fresh, banana, sweet & ND & $\mathrm{ND}$ & $\mathrm{ND}$ & 6,093 & 21,054 & ND & 50 \\
\hline Hexyl acetate & Fruity, apple, pear & ND & 1,119 & 489 & $\mathrm{ND}$ & 6,986 & 2,500 & 55 \\
\hline Ethyl butyrate & Fruity, papaya, butter, sweet, apple, perfumed & 1,305 & 638 & ND & $\mathrm{ND}$ & 1,328 & 609 & 56 \\
\hline Ethyl hexanoate & Fruity, apple, banana & 26,624 & 7,268 & 1,883 & 367 & 28,208 & 11,697 & 49 \\
\hline Ethyl octanoate & Pineapple, peer & 56,857 & 34,670 & 3,126 & 1,259 & 54,932 & 5,691 & 49 \\
\hline Ethyl decenoate & Sweet, fatty, nut-like & 34,443 & 15,513 & 1,279 & 554 & 25,499 & 16,352 & 15 \\
\hline Phenethyl acetate & Floral, fruity, sweet & 4,307 & $\mathrm{ND}$ & 5,322 & $\mathrm{ND}$ & 4,472 & 1,888 & 50 \\
\hline
\end{tabular}

${ }^{11} \mathrm{ND}$, not detected.

발효구에서 동결농축 후 감소하였으며, I. orientalis KMBL5774 혼합발효구에서는 증가하였다. Intensity value 에서는 모든 시료구에서 수치가 2 배 가까이 증가하였다. Hunter's color value 분석 결과, 동결농축 후 모든 사과와인 의 $\mathrm{L}$ value와 $\mathrm{a}$ value가 유의적으로 감소하였으며, $\mathrm{b}$ value는 유의적으로 증가하였고, 이는 동결농축 공정 중 사과와인 의 성분 농축에 의한 결과로 보여진다.

동결농축에 따른 사과와인의 휘발성 향기 성분 함량의 변화를 관찰한 결과를 Table 4 에 나타내었다. 와인의 향기 성분은 와인의 품질을 결정짓는 중요한 요소이며, esters,aldehydes, ketones, terpenes, acids, alcohols, sulfur compounds 등의 서로 다른 화합물의 복합적인 작용으로 인해 다양한 향기성분이 형성된다(44). 정량적 관점에서 사과와인의 휘발성 향기 성분 중 대부분을 차지하는 것은
알코올류로서, 총 7종의 알코올류가 검출되었다. 과실을 이용한 와인발효 시 다양한 효모들은 고급알코올의 농도와 종류에 상당한 영향을 받는다(45). 효모 대사와 고급알코올 의 밀접한 관련성 때문에, 과실류 와인의 알코올 농도는 효모균주의 발효능을 보여주는 중요한 지표이다(46). Fusel oil을 구성하는 고급 알코올류에서 검출되는 향기 성분인 1-propanol 함량의 경우 S. cerevisiae Fermivin 단독발효구 에서 가장 높은 것을 확인하였고, 나머지 발효구에서도 동 결농축 후 함량이 증가하였다. Isobutyl alcohol과 isoamyl alcohol의 경우, 앞선 퓨젤유 분석과 마찬가지로 동결농축 후 함량이 증가하는 것을 확인하였으며, 1-hexanol, 1-heptanol, phenethyl alcohol, 2-nonanol의 경우 동결농축 후 대부분 감소하였고, 일부 발효구에서 거의 유사한 함량 을 나타내었다. 
Table 5. Sensory scores of apple ciders fermented by Saccharomyces cerevisiae Fermivin (Fermivin), mixed culture of $S$. cerevisiae Fermivin and Pichia anomala JK04 (Fermivin+JK04), mixed culture of $S$. cerevisiae Fermivin and Issatchenkia orientalis KMBL5774 (Fermivin+KMBL5774) after freeze concentration

\begin{tabular}{lccccc}
\multicolumn{1}{c}{ Sample } & Color & Flavor & Taste & Sourness & Overall preference \\
\hline Fermivin & $5.20 \pm 0.27^{1 / 2)}$ & $4.67 \pm 0.21^{\mathrm{a}}$ & $4.27 \pm 0.26^{\mathrm{b}}$ & $4.53 \pm 0.30^{\mathrm{a}}$ & $4.60 \pm 0.21^{\mathrm{b}}$ \\
Fermivin+JK04 & $5.63 \pm 0.21^{\mathrm{a}}$ & $4.97 \pm 0.20^{\mathrm{a}}$ & $4.47 \pm 0.27^{\mathrm{b}}$ & $4.40 \pm 0.24^{\mathrm{a}}$ & $4.77 \pm 0.25^{\mathrm{b}}$ \\
Fermivin+KMBL5774 & $5.33 \pm 0.22^{\mathrm{a}}$ & $4.70 \pm 0.28^{\mathrm{a}}$ & $5.70 \pm 0.24^{\mathrm{a}}$ & $4.37 \pm 0.27^{\mathrm{a}}$ & $5.57 \pm 0.23^{\mathrm{a}}$ \\
\hline
\end{tabular}

${ }^{1)}$ The values were expressed as mean \pm SD $(n=3)$.

${ }^{2)}$ Different letters within the same column indicate significant difference $(\mathrm{p}<0.05)$.

에스테르 화합물은 발효 과정에서 acetyl-CoA의 도움으 로 효소적 에탄올 분해 작용에 반응하는 전구체들로부터 합성되며 와인의 관능적인 부분에서 좋은 맛, 향을 부여한 다고 알려져 있다 $(47,48)$. 본 실험에서 에스테르류 화합물 은 10 종이 검출되었다. Methyl acetate의 경우, P. anomala $\mathrm{JK} 04$ 혼합발효구에서만 검출되었으며, 동결농축에 의해 함량이 증가하였다. Ethyl acetate의 경우, 혼합발효구에서 S. cerevisiae Fermivin 단독발효구보다 높게 측정되었으며, P. anomala JK04 혼합발효구를 제외하고는 동결농축에 의 해 감소하였다. Isobutyl acetate와 isoamyl acetate는 $S$. cerevisiae Fermivin 단독발효구에서는 동결농축 전후로 검 출되지 않았으며, 동결농축 후에는 $P$. anomala JK04 혼합발 효구에서만 검출되었다. Hexyl acetate의 경우, S. cerevisiae Fermivin 단독발효구에서는 동결농축 전 검출되지 않았으 나, 동결농축 후 일부 검출되었으며, 혼합발효구들에서는 동결농축 후 감소하여 P. anomala JK04 혼합발효구는 불검 출, I. orientalis KMBL5774 혼합발효구는 일부 검출되었다. 나머지 향기성분인 ethyl butyrate, ethyl hexanoate, ethyl octanoate, ethyl decenoate, phenethyl acetate는 $S$. cerevisiae Fermivin 단독발효구가 대체로 혼합발효구들보다 높거나 비슷한 함량이 검출되었으나 동결농축 후에는 모든 발효구 에서 함량이 감소하였다. Acid류는 KMBL5774 혼합발효구 에서는 동결농축 전후로 아무것도 검출되지 않았으며, $P$. anomala JK04 혼합발효구에서는 유기산 분석과 마찬가지 로 acetic acid가 일부 검출되어 동결농축에 의해 함량이 증가하였다. 휘발성향기성분 분석결과를 종합할 때, 향기 성분에 중요한 역할을 하는 저분자 ester 화합물들이 혼합발 효구들에 의해 형성된 것으로 보아 관능적 품질에 긍정적인 영향을 주었을 것으로 판단된다.

\section{동결농축 사과와인의 관능평가}

동결농축된 사과와인의 관능평가 결과를 Table 5에 나타 내었다. 관능검사 결과, 색, 향, 신맛의 경우에는 통계적으 로 유의적인 차이가 발견되지는 않았으나, 모든 항목에서 대조구인 S. cerevisiae Fermivin 단독발효구보다 nonSaccharomyces 혼합발효구에서 높은 점수를 받았으며, 색 과 향에서는 P. anomala JK04 혼합발효구가, 맛과 전반적인
기호도에서는 I. orientalis KMBL5774 혼합발효구가 가장 높은 점수를 받았다. 신맛의 경우에는 대조구인 $S$. cerevisiae Fermivin 단독발효구가 신맛이 가장 강한 것으로 나타났으며, malic acid 감산능을 지니고 있는 I. orientalis KMBL5774 혼합발효구에서 신맛이 가장 약한 것으로 나타 났다. 이는 P. anomala JK04가 발효 과정 중 다양한 향기성 분을 생성하여 와인의 향미를 증진시킨다는 Kwon 등(15) 과 Jeong 등(26)의 연구와 일치하였으며, I. orientalis KMBL5774가 malic acid를 감소시켜 와인의 신맛을 감소시 킨다는 Seo 등(17)과 $\mathrm{Kim}$ 등(19)의 연구와 일치하였다.

\section{요 약}

본 연구는 non-Saccharomyces 효모와 $S$. cerevisiae Fermivin으로 혼합발효된 사과와인을 동결농축하였을 때, 이화학적 특성의 변화를 관찰하여 고품질 무가당 사과와인 의 가능성을 알아보았다. 이를 위해 향미 증진능을 지닌 것으로 알려진 P. anomala JK04와 malic acid 분해능을 지닌 I. orientalis KMBL5774 효모를 사용하였으며, 혼합발효 후 알코올 함량이 $12 \%(\mathrm{v} / \mathrm{v})$ 가 되도록 동결농축하였다.

P. anomala JK04 혼합발효구는 다른 시험구와 비교하여 발효속도가 늦어 발효를 완전히 진행시키지 않았다. 동결 농축 후 이화학적 특성의 변화를 관찰하였을 때, P. anomala $\mathrm{JKO4}$ 혼합발효구의 당도, 환원당, 총산, 총 페놀성 화합물의 함량이 다른 시험구보다 높게 측정되었으며, 다른 시험구 들도 동결농축 후 해당 성분들의 함량이 증가하였다. $P$. anomala JK04 혼합발효구의 유리당 함량이 상대적으로 높 게 검출되었으며, 동결농축 후 2-3배 증가하였다. 유기산의 경우, lactic acid를 제외한 모든 유기산의 함량이 동결농축 후 증가하였으며 모든 시험구에서 malic acid 함량이 가장 높게 측정되었다. I. orientalis KMBL5774는 malic acid 감산 능력을 지니고 있어 malic acid 함량이 다른 시험구보다 낮게 검출되었다. 메탄올, 아세트알데히드, 퓨젤유의 경우, 동결농축에 의하여 함량이 증가하였으나 식품공전상 허용 기준치보다 낮게 검출되었다. 사과와인의 색도 분석에서는 hue value는 $S$. cerevisiae Fermivin 단독발효구와 P. anomala 
$\mathrm{JK} 04$ 혼합발효구에서 동결농축 후 감소하였으나, I. orientalis KMBL5774 혼합발효구에서는 증가하였으며, intensity value는 모든 시료구에서 2 배 가량 증가하였다. $\mathrm{L}$ 과 a value는 모든 시험구에서 동결농축 후 감소하였으며, $\mathrm{b}$ value는 증가하였다. 총 20 종의 휘발성 향기성분이 검출 되었으며, 상대적으로 저분자에 속하는 알코올류와 에스테 르류 들의 함량이 동결농축 후 증가하였으며, 고분자에 속 하는 물질들의 함량은 감소하였다. 관능평가 결과, non-Saccharomyces를 이용한 혼합발효구 모두 대조구보다 우수한 결과를 얻었으며, 특히 P. anomala JK04 혼합발효구 는 색과 향미에서, I. orientalis KMBL5774 혼합발효구는 맛과 전반적인 기호도에서 가장 우수한 결과를 얻었다.

본 연구 결과, 동결농축된 사과와인에서 다양한 성분들 이 축적되어 새로운 무가당 사과와인 제품 개발의 가능성을 나타내었으며, non-Saccharomyces 효모 혼합발효는 사과와 인의 품질 향상을 이룰 것으로 기대된다.

\section{감사의 글}

본 연구는 2018년 농촌진흥청 어젠다 과제(PJ012425022018) 의 연구비 지원에 의해 수행되었으며 이에 감사드립니다.

\section{References}

1. Yang HJ, Ryu GH (2010) Preparation and characterization of Jochung, a grain syrup, with apple. J Korean Soc Food Sci Nutr, 39, 132-137

2. Seo JH, Lee GD, Jeong YJ (2001) Optimization of the vinegar fermentation using concentrated apple juice. $\mathrm{J}$ Korean Soc Food Sci Nutr, 30, 460-465

3. Kwak HS, Seo JS, Bae H, Lee H, Lee Y, Jeong Y, Kim M (2016) Effect of fermentation temperature on quality characteristics of apple wine. J Korean Soc Food Sci Nutr, 45, 155-159

4. Lea AG, Drilleau JF (2003) Cidermaking. In fermented beverage production, Springer, Boston, MA, USA, $p$ 59-87

5. Bang BH, Jeong EJ, Kang H, Rhee MS, Yi DH, Paik JK (2017) Effects of fining treatments on color and clearness of apple wine. J Korean Soc Food Sci Nutr, $46,368-373$

6. Choi SH, Choi YJ, Lee AR, Park SA, Kim DH, Baek SY, Yeo SH, Rhee CH, Park HD (2011) Fermentation characteristics of freeze-concentrated apple juice by Saccharomyces cerevisiae isolated from Korean domestic grapes. Korean J Food Preserv, 18, 559-566

7. Choi SH, Baek SY, Yeo SH, Park HD (2012) Rapid fermentation of freeze-concentrated ice apple wine by a sugar tolerant yeast, Saccharomyces cerevisiae SS89. Korean J Food Preserv, 19, 413-419

8. Han WC, Ji SH, Lee JC, Cheong C, Kang SA, Jang $\mathrm{KH}$ (2009) Quality characteristics of apple wine fermented with Rosa rugosa Thunb. Korean J Food Preserv, 16, 311-316

9. Nam CU (2008) Fermentation characteristics of freeze-concentrated apple juice to make apple ice wine. MS Thesis, Kyungpook National University, Korea, $\mathrm{p}$ $1-4,54$

10. Hernandez E, Raventos M, Auleda JM, Ibarz A (2010) Freeze concentration of must in a pilot plant falling film cryoconcentrator. Innovative Food Sci Emerging Technol, 11, 130-136

11. Raventos M, Hernandez E, Auleda J, Ibarz A (2007) Concentration of aqueous sugar solutions in a multi-plate cryoconcentrator. J Food Eng, 79, 577-585

12. Miyawaki $\mathrm{O}$, Gunathilake $\mathrm{M}$, Omote $\mathrm{C}$, Koyanagi $\mathrm{T}$, Sasaki T, Take H, Matsuda A, Ishisaki K, Miwa S, Kitano S (2016) Progressive freeze-concentration of apple juice and its application to produce a new type apple wine. J Food Eng, 171, 153-158

13. Liu L, Miyawaki O, Hayakawa K (1999) Progressive freeze concentration of tomato juice. Food Sci Technol Res, 5, 108-112

14. Ramos FA, Delgado JL, Bautista E, Morales AL, Duque C (2005) Changes in volatiles with the application of progressive freeze-concentration to Andes berry (Rubus glaucus Benth). J Food Eng, 69, 291-297

15. Kwon SJ, Choi JS, Yeo SH, Park HD (2015) Fermentation characteristics of persimmon wine by the mixed culture of Pichia anomala JK04 and Saccharomyces cerevisiae Fermivin cells. Korean J Food Preserv, 22, 768-777

16. Rojas V, Gil JV, Pinaga F, Manzanares P (2001) Studies on acetate ester production by non-Saccharomyces wine yeasts. Int J Food Microbiol, 70, 283-289

17. Seo SH, Rhee CH, Park HD (2007) Degradation of malic acid by Issatchenkia orientalis KMBL 5774, an acidophilic yeast strain isolated from Korean grape wine pomace. J Microbiol, 45, 521-527

18. Hwang BH (2015) Fermentation characteristics of persimmon wine by the mixed culture of Issatchenkia orientalis KMBL 5774 and Saccharomyces cerevisiae 
Fermivin. MS Thesis, Kyungpook National University, Korea, p 25-28

19. Kim DH, Hong YA, Park HD (2008) Co-fermentation of grape must by Issatchenkia orientalis and Saccharomyces cerevisiae reduces the malic acid content in wine. Biotechnol Lett, 30, 1633-1638

20. Jeong EJ, Kim HE, Shin DH, Kim YS (2007) Effect of pectinase treatment on the extraction yield improvement from Rubus coreanus juice and physicochemical characteristics during alcohol fermentation. Korean J Preserv, 14, 702-708

21. Ahmed H (2004) Principles and reactions of protein extraction, purification and characterization. CRC Press, London, England, p 350-352

22. Liquors Licence Aid Center (2010) Code for analysis of alcoholic beverages. National Tax Service, Seoul, Korea, p 39, 104-202

23. AOAC (1990) Official methods of analysis. $15^{\text {th }}$ ed, Association of Official Analytical Chemists, Washington, DC, USA, p 40-84

24. Folin O, Ciocalteu V (1927) On tyrosine and tryptophane determinations in proteins. $\mathrm{J}$ Biol Chem, 73, 627-650

25. Singleton VL, Rossi JA (1965) Colorimetry of total phenolics with phosphomolybdic-phosphotungstic acid reagents. Am J Enol Vitic, 16, 144-158

26. Jeong HS, Lee SB, Yeo SB, Kim DH, Choi JS, Kim DH, Yeo SH, Park HD (2017) Blending effect of Campbell Early and aronia wines fermented by the mixed culture of Pichia anomala JK04 and Saccharomyces cerevisiae Fermivin. Korean J Preserv, 24, 472-482

27. Zoecklein BW, Fugelsang KC, Gump BH and Nury FS (1990) Production wine analysis. Van Nostrand Reinhold, New York, NY, USA, p 129-168

28. SAS (2004) SAS/STAT 9.3 user's guide. SAS Institute Inc, Cary, NC, USA, p 313-383

29. Park WM, Park HG, Rhee SJ, Kang KI, Lee CH, Yoon KE (2004) Properties of wine from domestic grape, Vitis labrusca cultivar. Campbell's Early, fermented by carbonic maceration vinification process. Korean J Food Sci Technol, 36, 773-778

30. Kim MS, Park HD (2014) Reduction in the contents of acetaldehyde, methanol and fusel alcohols in the Muscat Bailey A wine fermented by Korean indigenous sugar-tolerant yeasts Saccharomyces cerevisiae S13 and D8. Korean J Food Preserv, 21, 851-858

31. Park WM, Park HG, Rhee SJ, Lee CH, Yoon KE (2002) Suitability of domestic grape, cultivar Campbell's Early, for production of red wine. Korean J Food Sci Technol, 34, 590-596

32. Choi YJ (2011) Fermentation characteristics of for different apple varieties by commercial wine yeasts. MS Thesis, Kyungpook University, Korea, p 20-21

33. Halliwell B (2000) The antioxidant paradox. The Lancet, 355, 1179-1180

34. Rankine BC (1967) Formation of higher alcohols by wine yeasts, and relationship to taste thresholds. J Sci Food Agric, 18, 583-589

35. Amerine MA, Roessler EB, Ough CS (1965) Acids and the acid taste: I. The effect of $\mathrm{pH}$ and titratable acidity. Am J Enol Vitic, 16, 29-37

36. Silva ML, Malcata FX (1998) Relationships between storage conditions of grape pomace and volatile composition of spirits obtained therefrom. Am J Enol Vitic, 49, 56-64

37. MFDS (2013) Food code. Ministtry of Food and Drug Safety, Cheongju, Korea, p 5-27-7

38. Miyake T, Shibamoto T (1993) Quantitative analysis of acetaldehyde in foods and beverages. J Agric Food Chem, 41, 1968-1970

39. Koh KH, Chang WY (1998) Changes of chemical components during Seibel white grape must fermentation by different yeast strains. Korean J Food Sci Technol, 30, 487-493

40. Chung H, Yoon MK, Kim M, Park SK, Lee J, Kim YS (2012) Volatile hazardous compounds in alcoholic beverages. J Appl Biol Chem, 55, 141-148

41. In HY, Lee TS, Lee DS, Noh BS (1995) Volatile components and fusel oils of Sojues and mashes brewed by Korean traditional method. Korean J Food Sci Technol, 27, 235-240

42. Lachenmeier DW, Haupt S, Schulz K (2008) Defining maximum levels of higher alcohols in alcoholic beverages and surrogate alcohol products. Regul Toxicol Pharmacol, 50, 313-321

43. Ribereau-Gayon P, Glories Y, Maujean A, Dubourdieu D (2006) Handbook of enology, the chemistry of wine: stabilization and treatments. Wiley \& Sons, New york, NY, USA, p 129-185

44. Vas G, Gal L, Harangi J, Dobo A, Vekey K (1998) Determination of volatile aroma compounds of Blaufrankisch wines extracted by solid-phase microextraction. J Chromatogr Sci, 36, 505-510

45. Vilanova M, Sieiro C (2006) Contribution by Saccharomyces cerevisiae yeast to fermentative flavour 
compounds in wines from cv. Albarino. J Ind Microbiol Biotechnol, 33, 929-933

46. Romano P, Fiore C, Paraggio M, Caruso M, Capece A (2003) Function of yeast species and strains in wine flavour. Int J Food Microbiol, 86, 169-180

47. Swiegers JH, Pretorius IS (2005) Yeast modulation of wine flavor. Adv Appl Microbiol, 57, 131-175

48. Lee MS (2012) Changes of physico-chemical sensory and volatile profiles of commercial Makgeolli during storage. MS Thesis, Sejong University, Korea, p 37-48

49. Sun SY, Che CY, Sun TF, Lv ZZ, He SX, Gu HN, Shen WJ, Chi DC, Gao Y (2013) Evaluation of sequential inoculation of Saccharomyces cerevisiae and Oenococcus oeni strains on the chemical and aromatic profiles of cherry wines. Food Chem, 138, 2233-2241

50. Jeong EJ, Jeon SY, Baek JH, Cha YJ (2011) Volatile flavor compounds in commercial vinegar beverages derived from fruits. J Life Sci, 21, 292-299

51. Jiang B, Zhang Z (2010) Volatile compounds of young wines from Cabernet Sauvignon, Cabernet Gernischet and Chardonnay varieties grown in the Loess Plateau region of China. Molecules, 15, 9184-9196
52. Lin FM, Wilkens WF (1970) Volatile flavor components of coconut meat. J Food Sci, 35, 538-539

53. Molina AM, Swiegers JH, Varela C, Pretorius IS, Agosin E (2007) Influence of wine fermentation temperature on the synthesis of yeast-derived volatile aroma compounds. Appl Microbiol Biotechnol, 77, 675-687

54. Hernández-Orte P, Pena A, Pardo I, Cacho J, Ferreira V (2012) Amino acids and volatile compounds in wines from Cabernet Sauvignon and Tempranillo varieties subjected to malolactic fermentation in barrels. Food Sci Technol Int, 18, 103-112

55. Dixon J, Hewett EW (2000) Factors affecting apple aroma/flavour volatile concentration: A review. N Z J Crop Hortic Sci, 28, 155-173

56. Duarte WF, Dias DR, Oliveira JM, Vilanova M, Teixeira JA, Almeida e Silvar JB, Schwan RF (2010) Raspberry (Rubus idaeus L.) wine: Yeast selection, sensory evaluation and instrumental analysis of volatile and other compounds. Food Res Int, 43, 2303-2314 